quently appeared in American journals. Criticism which ignores all that is good, and exaggerates all that is imperfect, in the work of any specialist, especially in that of so eminent a master as Dr. Günther, is greatly to be deprecated. G. Brown Goode.

Washington, June 1.

\section{'A singular optical phenomenon.'}

With reference to the 'optical illusion' to which your correspondent ' F. J. S.' drew attention (Science, No. 57, p. 275), and which has been abundantly illustrated and explained in later numbers, may I suggest to your readers who have not yet witnessed the phenomenon, to beg, borrow, or buy a few square inches of that finely perforated card which ladies were accustomed to use a good deal for working bookmarkers, initials, and the like.

There are several ways of using it with good effect. $1^{\circ}$. Before cutting the sheet, use it with a hand-mirror, standing $(a)$ with the back to the light, and looking through both the real and the reflected cards; $(b)$ facing the light, and looking through the one, at the other. $2^{\circ}$. Cut off a strip if the quantity available is restricted: otherwise divide in two more equal portions, and holding the smaller in one hand, between the eye and the larger, vary the distances absolutely and relatively, and also the relative inclinations (in their proper parallel planes); in this case, also, varying the position with respect to the light. $3^{\circ}$. Use the same close to a strong light, in such a way that the first surface (and the fourth) shall be in shade, while the second, and more especially the third, shall be in strong light.

The variations possible are, of course, far too numerous to admit of categorical statements. Still less can I attempt to describe what is seen. Nor, indeed, would it be a sensible proceeding to describe what is at once so easy, and so very much more interesting to see. My object is merely to point out the means and the manner.

I will, however, mention two of the more curious aspects presented. $1^{\circ}$. When a luminous background is seen through the reflected screen, and the latter is moved freely about in its own plane (which, of course, is supposed parallel to the glass), the phantom screen remains stationary. $2^{\circ}$. When one screen is held at arm's length, and the other two or three inches nearer to the eye, so as to produce a phantom some three or four times the size of the real pattern, the circumstances are favorable for concentrating attention on the contrast of colors presented. What I see is a sharply-defined rectangular network, as of blue steel wires with secondary and tertiary nets of doubtful color and indistinct form. As the intermediate screen is brought nearer to the eye, up to halfway, the intensity of color of the blue netting is much increased. I cannot pretend to give an exact indication, as I have only made a sort of hasty reconnoissance of this field. I notice, however, that the phenomenon presented by inclining the axes of the patterns to each other produces a wonderfully kaleidoscopic appearance.

To pursue the experiments, I should wish to use different patterns of perforation, and differently colored lights.

23 Suffolk Street, Pall Mall East, J. HeRscheL. London.

\section{Guyot's 'Creation.'}

In the notice of Guyot's 'Creation' there is an error which makes me say precisely the opposite of my meaning. On p. 601, first column, fifth line, for ' only' read 'more than.' WRITER OF THE NOTICE.

\section{PRESIDENT ELIOT ON A LIBERAL EDUCATION.}

President Eliot's address before the Johns Hopkins university in February last, which appears in the June Century, though radical from one point of view, is not so from another. In maintaining that Greek should no longer be an indispensable requisite to the bachelor's degree, he takes what the conservative educators must regard as very radical ground. But when we examine what he would substitute for Greek, and what studies he regards as affording the most profitable culture, we see that he does not take the same view as the advocates of scientific education. The studies which he would elevate as at least co-equal with Greek, are the English language and literature, the French and German languages, history, political economy, and natural science. A careful examination will show that this proposed change would not be the substitution of a scientific for a literary culture, but rather the contrary. The leading studies in literature are now Greek and Latin; the modern languages, literature and history, being confessedly taught in a comparatively imperfect way. By adding history and the three modern languages to the curriculum from which the student makes his choice, a very large addition is made to the literary side of the banquet. This addition is hardly compensated by the increased consideration which he would give to political economy and natural science.

While it seems, therefore, that we can hardly regard President Eliot as a pronounced partisan of a scientific education, it must be admitted that the ground taken by those who are such partisans is not very definite. Their stereotyped complaint is that too much attention is given to languages and mathematics. Scientific studies are thus placed in contradistinction to those two subjects. Now, comparing our own education with that of other countries, it can hardly be claimed that we pay disproportionate attention to either mathematics or languages in this country. Not only is our mathematical education far behind that of France and Germany, but a much better mathematical training than our average student gets is absolutely necessary to an adequate comprehension of modern physical science. To take an example: it is safe to say that the number of our college graduates who know mathematics enough to understand clearly what physicists mean by the terms ' conservation' and 'transformation of energy,' is very small. One fact well worthy of consideration on both sides is, that, notwithstanding that the Germans 
are among the foremost in scientific research, they are also far ahead of us in the thoroughness with which they learn the modern languages and mathematics. It is probably safe to say, that the average doctor of philosophy who has just graduated from a German university speaks and understands both French and English better than nine-tenths of American masters of arts speak or understand either French or German; that he reads Greek equally well with his American compeer, and Latin a great deal better; he also has as good command of mathematics as the best half of the American graduates, and possibly as good a command as the average American professor of our three hundred colleges. It would seem, therefore, that the whole story is not told, when it is claimed that the two studies alluded to, receive a disproportionate share of attention.

President Eliot does not define very fully what he includes under the head of natural science; but as he would give no more attention than at present to mathematics, and as such attention is absolutely necessary to any improvement in our general understanding of a physical science, we may assume that he refers principally to the biological sciences, especially botany, zoölogy, and animal and vegetable physiology. The advocates of a scientific education will probably reply, that it depends altogether on the way in which natural science is taught, whether it should take a more prominent place in the curriculum. If the teaching is confined to the regular routine of the past, and is to terminate in the ability of the student to name and describe the plants and animals which he may meet with in his rambles, a very little will suffice, though that little may be important.

With this great addition to the curriculum, it is evident that no one student can master the whole, or any considerable portion of the whole. The president of Harvard is well known as an advocate for the optional character of studies : in fact, he would permit option much earlier than it is now permitted. Yet as he would require, as a condition of admission to colleges, a proficiency in three out of the four languages, - French, German, Latin, and Greek, - he would, perhaps, not go so far in this direction as one might suppose from the general tenor of his discourse. In fact, from what he had just said of the extremely imperfect character of the knowledge which a student can possibly get of Greek and Latin in the usual course, - of metaphysics from a single text-book of moderate size, of physics from a manual of a few hundred pages, of political economy from a single short treatise, - it would be inferred that he considers such imperfect knowledge as not worth acquiring. Howerer this may be, it is certain, that, in permitting a student to choose from the beginning that subject for which he has the most capacity, President Eliot gives expression to a very popular view of the subject ; but there is something to be said on the other side. One of the great objects of a liberal education is to secure community and sympathy of thought and feeling among the great body of educated men. If, now, among these men, are found very different natural aptitudes for special studies, it is clear that the end will be best reached by adopting a system of training for every man in that class of subjects for which his natural capacity is the weakest. If, as the writer suspects, the actual differences of capacity are not so great as the apparent differences in facility of acquisition on the current system, and if the apparent lack of talent among students in special subjects arises principally from those subjects not being presented to them in the way in which their minds are best able to grasp them, we may entertain a reasonable hope of coming nearer a common system of culture by suiting the method of teaching to the pupil.

The writer does not think that President Eliot squarely hits the point, when he indicates a preference for a thorough study of some one subject over what he considers an imperfect knowledge of a number of subjects. Properly speaking, a thorough knowledge of any one subject belongs to a professional, and not to a liberal education. 'The author can do little more than repeat, what he has probably said more than once before, that the main object of a liberal education should not be minuteness of knowledge, but a thorough understanding and mastery of those elementary ideas which form the foundation of all knowledge. If any system of training can be discovered which will enable the student to see the economical fallacies to which all men seem to be liable, on the subjects of the currency, the employment of labor, and the protection of home industry, as plainly as he sees the same fallacies when applied to his own every-day work, then that system would have the highest claims upon us, as supplying what was wanted to form a liberal education. The text-books adapted to such a system would be small; but they would have to be supplemented by a large amount of work, on the part of the living teacher, of a different kind from that commonly expected of him in this country.
S. Newcomb. 